\title{
Prevalence, timing, and predictors of transitions from inhalant use to Inhalant Use Disorders
}

\author{
Brian E. Perron ${ }^{\mathrm{a}, *}$, Matthew O. Howard ${ }^{\mathrm{b}}$, Samopriyo Maitra ${ }^{\mathrm{a}}$, Michael G. Vaughn ${ }^{\mathrm{c}}$ \\ a University of Michigan, Ann Arbor, MI 48109, USA \\ b University of North Carolina, Chapel Hill, NC 27599, USA \\ c Saint Louis University, St. Louis, MO 63103, USA
}

\section{A R T I C L E I N F O}

\section{Article history:}

Received 11 July 2008

Received in revised form 4 October 2008

Accepted 18 October 2008

Available online 16 December 2008

\section{Keywords:}

Inhalants

Inhalant Use Disorders

NESARC

Volatile solvents

\begin{abstract}
A B S T R A C T
Background: Few studies of the natural history of DSM-IV inhalant substance use disorders (I-SUDs) have been conducted. This investigation examined the prevalence, timing, and predictors of transitions from inhalant use to formal I-SUDs among inhalant users within a nationally representative sample.

Methods: Participants were 664 U.S. residents participating in the 2000-2001 National Epidemiologic Survey on Alcohol and Related Conditions who reported lifetime inhalant use. Respondents completed structured interviews assessing DSM-IV psychiatric/substance use disorders. Bivariate and Cox regression analyses were conducted to identify risk factors for transitions from inhalant use to I-SUDs.

Results: Nearly one in five (19.4\%) persons initiating inhalant use developed an I-SUD. Most I-SUD transitions were to inhalant abuse rather than inhalant dependence. Risk for development of I-SUDs was greatest in the first year following initiation of inhalant use and low thereafter. Multivariate proportional hazards models indicated that presence of a mood/anxiety disorder $(\mathrm{HR}=7.7, \mathrm{CI}=3.1-18.9)$ or alcohol use disorder $(\mathrm{HR}=11.9, \mathrm{CI}=5.46-26.00)$ antedating initiation of inhalant use predicted significantly elevated risk for I-SUDs, whereas being married conferred a lower risk for onset of I-SUDs.

Conclusions: I-SUDs were relatively common among inhalant users, generally occurred in the year following initiation of inhalant use, and were associated with early-onset mood/anxiety and alcohol use disorders. Given the young average age at onset of inhalant use and the rapidity with which most I-SUDs developed, interventions directed to adolescents who have initiated inhalant use might be effective in reducing the proportion of inhalant users who develop I-SUDs.
\end{abstract}

(C) 2008 Elsevier Ireland Ltd. All rights reserved.

\section{Introduction}

Long neglected in the substance abuse research and clinical literatures, inhalant use has been the focus of comparatively intensive investigation in recent years (Medina-Mora and Real, 2008; Ridenour, 2005). National surveys in the U.S. indicate that purposive inhalation of volatile solvents by the citizenry may be more prevalent than generally recognized. For example, Wu and Ringwalt (2006) reported that approximately $10.0 \%$ of the 73,396 adults participating in the 2002-2003 National Surveys on Drug Use and Health had used inhalants. Monitoring the Future findings indicated that $15.6 \%$ of U.S. 8th graders in 2007 had tried inhalants (Johnston et al., 2008). Lifetime inhalant use is even more pervasive in many clinical

\footnotetext{
* Corresponding author at: School of Social Work, 1080 South University Avenue, University of Michigan, Ann Arbor, MI 48109, USA. Tel.: +1 7347639272.

E-mail address: beperron@umich.edu (B.E. Perron).
}

(Compton et al., 1994; Sakai et al., 2004) and criminological (Howard and Perron, 2008; McGarvey et al., 1999) client samples.

Inhalant use generally has been thought to have an early onset and high discontinuation rate (Crocetti, 2008; D'Abbs and MacLean, 2008). Combined data from the 2002 to 2006 administrations of the National Survey on Drug Use and Health indicated that past-year inhalant use was reported by $3.4 \%$ and $4.8 \%$ of U.S. 12 - and $13-$ year-olds, $5.3 \%$ and $5.1 \%$ of 14 - and 15 -year-olds, and $4.2 \%$ and $3.9 \%$ of 16- and 17-year-olds (SAMHSA, 2008). Thus, although annual prevalence rates were similar for the period spanning early-to-late adolescence, the highest prevalence rate for past-year inhalant use was observed among 14-year-olds. Similarly, Siqueira and Crandall (2006) found that lifetime inhalant use was most prevalent among 14 -year-olds in their survey of 60,345 Floridian students in 6th to 12 th grade.

Widespread inhalant use, though underappreciated, is a serious public health concern. Even a single episode of inhalant use can result in "sudden sniffing death" (Alper et al., 2008; Pfeiffer et al., 
2006). Many inhalants, such as gasoline, glue, and paint thinner are neurotoxic and capable of producing diffuse white matter changes associated with significant functional deficits (Finch and Lobo, 2005; Lubman et al., 2008). Reports of inhalant-related kidney, heart, and nerve damage are available in the scientific literature (e.g., Gautschi et al., 2007; Weintraub et al., 2000). Given the disproportionately scant empirical attention that inhalants receive in the broader substance abuse literature, Balster's recognition that inhalants are a "silent epidemic" still hold true today (Balster, 1997).

Widely used and medically consequential, inhalant use is also associated with a broad range of psychiatric comorbidities, substance use disorders, and adverse life circumstances. Ethnographic, national, and local survey studies suggest that inhalant users are found disproportionately among persons with poor school performance; the poor and otherwise socially marginalized; polydrug and IV-drug users; the mentally ill; youth with dysfunctional family backgrounds including parental alcoholism and criminality, poor or absent parenting, and histories of physical or sexual abuse; youth with deviant peer role models including friends who use inhalants; and persons with neuropsychological and learning disorders (D'Abbs and MacLean, 2008; Dinwiddie, 1998; Lubman et al., 2008). Inhalants are most apt to be abused by geographically and/or socially isolated persons who, by virtue of age, distance, or impoverishment, do not have access to other psychoactive agents (Dinwiddie, 1994; Oetting et al., 1988; Williams and Storck, 2007).

The majority of research on inhalant use has relied on survey methods. Although relatively few ethnographic studies have examined inhalant use, Seth et al. (2005) conducted one such investigation with 45 street children in Delhi, noting the key role played by inhalant-using peers in promoting onset of inhalant use, the low cost and ready availability of the toluene solution that was inhaled, and the occasional occurrence of inhalant-related withdrawal symptoms and overdose. Among the reported reasons for inhalant use were to cope with sadness, anger, and other negative emotional states, because it is pleasurable, and to cope with unpleasant work circumstances. Similar findings were reported in an ethnographic study of 31 Australian Aboriginal youth, who reported boredom and pleasure as among their chief reasons for inhalant use. Members of the local community regarded inhalant users as "scary," unpredictable, and social disenfranchised (Senior et al., 2006; see also MacLean, 2005, 2007).

In the only studies published to date of inhalant users participating in the National Epidemiologic Survey on Alcohol and Related Conditions (NESARC), the largest nationally representative comorbidity survey ever conducted in the U.S., Wu et al. (2008) reported that approximately $2 \%$ of NESARC respondents had a lifetime history of inhalant use, and approximately one-in-five inhalant users (19\%) had a lifetime inhalant use disorder. Among respondents with a lifetime history of inhalant use, $62 \%$ had a past-year and $96 \%$ had a lifetime DSM-IV substance use disorder. Psychiatric disorders were also prevalent among this sample of inhalant users. Nearly three-quarters (70\%) of inhalant users met criteria for one or more lifetime mood, anxiety, or personality disorders and 38\% had experienced a mood or anxiety disorder within the prior year (Wu and Howard, 2007). Other reports document high rates of suicidality (Freedenthal et al., 2007; Howard et al., 2008b), antisocial behavior (Compton et al., 2005; Howard et al., 2008c), substance use (Wu et al., 2008), and disadvantaged family and social life circumstances (Sakai et al., 2004) among inhalant users.

Research to date has focused largely on inhalant use rather than formal inhalant substance use disorders (I-SUDs). Little is known about the natural history of I-SUDs, particularly regarding factors that promote transitions from inhalant use to inhalant abuse and dependence. At present, there is no consensus as to the abuse liability of inhalants (i.e., proportion of inhalant users who progress to
I-SUDs). Anthony et al. (1994) reported that only 3.7\% of lifetime inhalant users participating in the National Comorbidity Survey met criteria for inhalant dependence. Sakai et al. (2004) found that although $18.0 \%$ of a clinical sample of adolescents $(N=847)$ had used inhalants, only 3.3\% met DSM-IV inhalant abuse or dependence criteria. High rates of abuse liability (40-50\%) were reported, however, by Howard and Perron (2008) and Ridenour et al. (2007) for samples of antisocial adolescents and community-residing inhalant users, respectively.

Whereas only limited and conflicting data are available regarding the abuse liability of inhalants, virtually no data (of which we are aware) are available identifying factors that predict the occurrence and timing of transitions from inhalant use to I-SUDs. To address these gaps in the literature, we utilized NESARC data to (1) evaluate the proportion and characteristics of lifetime inhalant users who progressed to I-SUDs and (2) identify factors predictive of the occurrence and timing of transitions from inhalant use to I-SUDs. Findings of this study may lead to better understanding of the natural history of I-SUDs and provide an empirical foundation for future I-SUD treatment and prevention interventions.

\section{Methods}

\subsection{Subjects, sampling, and interviews}

This study used data from the 2001 to 2002 NESARC, a representative sample of 43,093 U.S. adults (Grant et al., 2003), which gathered information on substance use and comorbid conditions from individuals living in households and group settings. NESARC utilized a multistage sampling design and had an overall response rate of 81\%. Data were weighted at the individual and household levels and adjusted for oversampling, nonresponse, and to be representative of the U.S. population vis-à-vis the 2000 census.

U.S. Census Bureau workers administered the alcohol use disorders and Associated Disabilities Interview Schedule (AUDADIS-IV), a structured interview designed for administration by lay interviewers. AUDADIS-IV assesses DSM-IV substance use disorders with good reliability (Grant et al., 1995, 2003). The NESARC survey, sampling protocol, related publications, and codebook are available at http://www.nesarc.niaaa.nih.gov/.

\subsection{Measurement}

\subsubsection{Inhalant use and I-SUDs}

Participants included lifetime inhalant nonusers and inhalant users. Inhalant users answered affirmatively to the question, "Have you ever used inhalants or solvents, for example, amyl nitrite, nitrous oxide, glue, toluene, or gasoline?" An introductory statement preceding the inhalant question informed respondents that they were to report inhalants used on their own, without a doctor's prescription, and for the purposes of getting high, enjoying themselves, relaxing, feeling better, feeling more alert, quieting their nerves, or to see how they would work. Inhalant abuse diagnoses were assigned to inhalant users who met DSM-IV inhalant abuse criteria but who did not meet inhalant dependence criteria; inhalant dependence diagnoses were assigned to subjects who met DSM-IV inhalant dependence criteria (American Psychiatric Association, 2000).

\subsubsection{Transitions from inhalant use to I-SUD}

The primary outcome in this study was the transition from inhalant use to a DSM-IV I-SUD (abuse or dependence). In bivariate analyses, this outcome was specified as a dichotomous variable, reflecting whether inhalant use developed into an I-SUD. In survival analyses (see analytic plan), the transition from inhalant use to an I-SUD was modeled as a time-to-event measure, capturing both the occurrence and timing of transitions from inhalant use to I-SUDs. The time-to-event was defined as the amount of time (in years) that elapsed between age at onset of inhalant use to the age at which I-SUD criteria were first met. Inhalant users who had not transitioned to I-SUDs at the time of the study were treated as right-censored observations, with the censoring time based on the difference between age at the time of NESARC interview and age at first inhalant use.

\subsubsection{Covariates}

Age at onset of inhalant use referred to the respondents' age at the time they first used inhalants. Lifetime DSM-IV drug use disorders included abuse or dependence on heroin, hallucinogens, cocaine/crack, marijuana, stimulants, painkillers, tranquilizers, and sedatives. Lifetime psychiatric disorder included diagnosis with a mood (depression, dysthymia, mania, and hypomania) or anxiety (social phobia, specific phobia, agoraphobia, panic, and generalized anxiety disorder) disorder. Lifetime 
DSM-IV alcohol use disorders included alcohol abuse or dependence. The AUDADIS IV established the age of onset for substance use and psychiatric disorders, which were used to specify whether or not they preceded onset of inhalant use. Lifetime DSM-IV conduct disorder and antisocial personality disorder were also included in this study. However, the AUDADIS-IV does not establish a time of onset for these disorders, so it was not possible to define whether or not they preceded inhalant use.

Response categories for region of residence in the U.S., race, gender, age, annual family income, and marital, educational, and unemployment status are listed in Table 1. Family histories of alcohol, drug, and antisocial behavior problems, respectively, were recorded as present/absent based on respondents' reports as to whether their biological parents (father and/or mother) had ever "been an alcoholic or problem drinker," had "problems with drugs," or had "behavior problems."

\subsection{Analytic plan}

Differences between inhalant users with and without I-SUDs were examined using chi-square $\left(\chi^{2}\right)$ tests for categorical variables and $t$-tests for continuous variables. Kaplan-Meier (K-M) estimates were computed to represent the unadjusted probability of surviving to each time point without transitioning to an I-SUD. These estimates are represented graphically in survival curves. Separate K-M estimates were computed for categorical variables, and a log-rank test was used to test group differences.

Cox proportional hazards regression analysis was used to examine factors associated with time-to-an-I-SUD following onset of inhalant use. Hazard ratios were derived to reflect the association between each variable and risk of transitioning to an I-SUD. Hazard ratios that did not include the value 1.00 in $95 \%$ confidence intervals were statistically significant.

Analyses were conducted using SUDAAN v. 9.0 (Research Triangle Institute, 2004). SUDAAN implements a Taylor series linearization to adjust standard errors of estimates for complex survey sampling design effects involving clustered data. SUDAAN does not provide the log-rank test for comparing group differences in $\mathrm{K}-\mathrm{M}$ survival estimates. Therefore, results produced by SUDAAN were compared with those produced by PROC LIFETEST using SAS. The results and standard errors produced by SAS and SUDAAN were nearly identical. Therefore, PROC LIFETEST was used to test for group differences.

\section{Results}

\subsection{Characteristics of inhalant users}

Approximately $74.2 \%$ of lifetime inhalant users were male and $82.2 \%$ were White (Table 1 ). The majority was unmarried and a substantial minority had a high school education or less. Only a small percentage of inhalant users had a DSM-IV drug use or alcohol use disorder that preceded inhalant use (7.8\% and 9.8\%). Approximately one in eleven (9.3\%) inhalant users had developed a DSM-IV mood and/or anxiety disorder prior to initiating inhalant use. Approximately one-third of the sample met criteria for conduct disorder or antisocial personality, and these disorders were not limited to those that preceded inhalant use onset. Approximately $22.2 \%$ had a family history of behavior problems, and $50.5 \%$ had a family history of substance use disorders. The mean age of onset of inhalant use was 17.5 years $(95 \% \mathrm{CI}=16.0-17.9)$, with a range of $5-44$.

Table 1

Socio-demographic and clinical characteristics of inhalant users with and without DSM-IV Inhalant Use Disorders.

\begin{tabular}{|c|c|c|c|c|}
\hline \multirow[t]{2}{*}{ Variable } & \multirow{2}{*}{$\begin{array}{l}\text { Overall }(N=664) \\
\% \text { (S.E.) }\end{array}$} & \multicolumn{3}{|l|}{ Inhalant users } \\
\hline & & $\begin{array}{l}\text { With an I-SUD } \\
(N=138) \%(\text { S.E. })\end{array}$ & $\begin{array}{l}\text { Without an I-SUD } \\
(N=526) \%(\text { S.E. })\end{array}$ & Chi-square $(p)$ \\
\hline Sex & & & & $.68(.414)$ \\
\hline Male & $74.2(2.02)$ & 77.7 (4.19) & $73.3(2.48)$ & \\
\hline Female & $25.8(2.02)$ & $22.4(4.19)$ & $26.7(2.48)$ & \\
\hline Annual family income past 12 months & & & & $1.62(.656)$ \\
\hline$<\$ 19,999$ & $28.4(2.21)$ & $33.1(5.3)$ & $27.2(2.30)$ & \\
\hline$\$ 20,000-34,999$ & $18.9(1.64)$ & $19.5(3.69)$ & $18.8(1.89)$ & \\
\hline$\$ 35,000-69,999$ & $31.8(2.15)$ & $30.1(5.42)$ & $32.2(2.42)$ & \\
\hline$\$ 70,000+$ & $20.9(2.01)$ & $17.4(4.27)$ & $21.8(2.20)$ & \\
\hline Region of United States & & & & $3.99(.273)$ \\
\hline Northeast & $21.7(4.02)$ & $17.8(4.65)$ & $22.6(4.23)$ & \\
\hline Midwest & $21.6(3.41)$ & $22.5(5.79)$ & $21.3(3.63)$ & \\
\hline South & $25.4(3.28)$ & $33.6(6.01)$ & $23.4(3.36)$ & \\
\hline West & $31.4(4.10)$ & $26.1(5.81)$ & $32.7(4.28)$ & \\
\hline Education & & & & $5.50(.071)$ \\
\hline Less than high school & $13.8(1.65)$ & $20.6(4.23)$ & $12.2(1.76)$ & \\
\hline High school & $27.2(2.39)$ & $30.4(4.65)$ & $26.4(2.58)$ & \\
\hline More than high school & $59.0(2.59)$ & $49.0(5.05)$ & $61.5(2.79)$ & \\
\hline Marital status & & & & $.95(.623)$ \\
\hline Married & $43.7(2.30)$ & $39.8(4.51)$ & $44.6(2.61)$ & \\
\hline Separated/widowed/divorced & $17.4(1.73)$ & $17.8(3.12)$ & $17.3(2.08)$ & \\
\hline Never married & $39.0(2.26)$ & $42.5(4.50)$ & $38.1(2.55)$ & \\
\hline Race & & & & $.62(.434)$ \\
\hline White & $82.2(1.74)$ & $79.6(3.76)$ & $82.9(1.97)$ & \\
\hline Non-White & $17.8(1.74)$ & $20.4(3.76)$ & $17.1(1.97)$ & \\
\hline Age of inhalant onset, mean (S.E.) & $17.5(.22)$ & $16.0(.38)$ & $17.9(.26)$ & $16.31(<.001)^{\mathrm{a}}$ \\
\hline Age of inhalant onset, median (S.E.) & $16.2(.20)$ & $15.1(.31)$ & $16.5(.22)$ & NA \\
\hline Established DSM-IV drug use disorder prior to onset of inhalant use ${ }^{\mathrm{b}}$ & $7.8(1.48)$ & $38.8(5.70)$ & $0.3(.32)$ & $26.30(<.001)$ \\
\hline Established DSM-IV alcohol use disorder prior to onset of inhalant use & $9.8(1.4)$ & $49.0(5.41)$ & $0.5(.35)$ & $42.3(<.001)$ \\
\hline DSM-IV antisocial personality or conduct disorder & $33.9(.52)$ & $46.8(5.07)$ & $30.8(2.49)$ & $7.52(.008)$ \\
\hline Established DSM-IV mood and/or anxiety disorder prior to onset of inhalant use & $9.3(1.30)$ & $43.8(4.61)$ & $1.0(.49)$ & $38.38(<.001)$ \\
\hline Family history of antisocial behavior problems & $22.2(1.90)$ & $24.2(4.49)$ & $21.8(2.14)$ & $.23(.633)$ \\
\hline Family history of substance use disorders & $50.5(2.31)$ & $60.4(5.17)$ & $48.1(2.59)$ & $4.35(.041)$ \\
\hline
\end{tabular}

Note: Values in bold are statistically significant $(p<.05)$; NA = not available.

a $F$-value.

b Abuse of or dependence on heroin, hallucinogens, cocaine/crack, marijuana, stimulants, painkillers, tranquilizers, and sedatives. 


\subsection{Bivariate associations with I-SUDs}

Overall, approximately $19.4 \%(N=138)$ of inhalant users transitioned from inhalant use to an I-SUD. Seventeen percent of inhalant users $17 \%(N=117)$ met criteria for inhalant abuse, and $2.3 \%(N=21)$ met criteria for dependence. Given the small sample of persons with inhalant dependence, inhalant abuse and dependence were combined for subsequent analyses involving I-SUDs.

No sociodemographic factors were significantly associated with transitions from inhalant use to an I-SUD. With the exception of family history of antisocial behavior, all clinical variables were predictive of elevated risks for development of I-SUDs. Specifically, among persons who transitioned from inhalant use to an I-SUD, $38.8 \%$ had a substance use disorder prior to initiating inhalant use, compared with only .3\% of inhalant users who did not develop an ISUD. A similar pattern was observed for preexisting mood/anxiety disorders (43.8\% transitioning to I-SUDs vs. 1.0\%). Inhalant users who transitioned to an I-SUD were also more likely to have a history of a DSM-IV conduct disorder and/or antisocial personality disorder (46.8\% vs. 30.8\%) and family history of substance use disorders (24.2\% vs. $21.8 \%$ ) compared with inhalant users who did not develop I-SUDs. Inhalant users who transitioned to an I-SUD were more likely to have an earlier mean age of inhalant use onset (16.0 years vs. 17.9 years).

\subsection{Transitions from inhalant use to an I-SUD}

The survival analysis was based on $97.6 \%$ of inhalant users $(N=648)$, as $2.4 \%$ of inhalant users with an I-SUD had missing values for their age of onset of an I-SUD. The mean age of onset for inhalant abuse was $17.0(95 \% \mathrm{CI}=15.9-18.1$; range $=6-53$; $N=103$ ); for inhalant dependence, it was 16.8 (95\% CI=14.8-18.9; range $=9-31 ; N=19$ ). Table 2 provides a summary of estimated survival probabilities for these inhalant users. These values represent the probability of surviving to that point in time (measured in years) without transitioning to an I-SUD (abuse or dependence). Thus, at 1 year following inhalant use onset, approximately $86 \%(95 \%$ $\mathrm{CI}=.82-.89$ ) of inhalant users had not developed an I-SUD. The greatest risk of transitioning to an I-SUD occurred during the first year following initiation of use and was consistently low thereafter. It should be noted that the discrepancy between the proportion of subjects who transitioned to an I-SUD and the estimated survival probability is due to censoring of observations and missing data.

Fig. 1a-f provides a graphical representation of $\mathrm{K}-\mathrm{M}$ survival probabilities for the first 10 years following initiation of inhalant use, stratified by each clinical variable that was statistically significant. These unadjusted curves were statistically significant based on a likelihood ratio test $(p<.001)$.

\section{Table 2}

Kaplan-Meier probabilities of not progressing to a DSM-IV Inhalant Use Disorder following initiation of inhalant use.

\begin{tabular}{lll}
\hline $\begin{array}{l}\text { Years from initiation } \\
\text { of inhalant use }\end{array}$ & $\begin{array}{l}\text { Kaplan-Meier survival } \\
\text { probability (S.E.) }\end{array}$ & $95 \% \mathrm{CI}$ \\
\hline 1 & $.86(.02)$ & $.82-.89$ \\
2 & $.84(.02)$ & $.79-.87$ \\
3 & $.83(.02)$ & $.78-.86$ \\
4 & $.82(.02)$ & $.78-.85$ \\
6 & $.82(.02)$ & $.78-.85$ \\
9 & $.81(.02)$ & $.77-.85$ \\
11 & $.81(.02)$ & $.77-.84$ \\
13 & $.81(.02)$ & $.76-.84$ \\
19 & $.80(.02)$ & $.76-.84$ \\
39 & $.77(.04)$ & $.67-.84$ \\
\hline
\end{tabular}

Note: S.E. = standard error; $\mathrm{CI}=95 \%$ confidence interval.
Table 3

Socio-demographic and clinical variables associated with onset of an Inhalant Use Disorder following first inhalant use based on Cox regression analysis.

\begin{tabular}{|c|c|c|}
\hline Variable & Hazard ratio & $95 \%$ confidence interval \\
\hline Age & 1.03 & $1.00-1.05$ \\
\hline \multicolumn{3}{|l|}{ Sex } \\
\hline Male & .65 & $.38-1.11$ \\
\hline Female & Ref & - \\
\hline \multicolumn{3}{|l|}{ Income past 12 months } \\
\hline$<\$ 19,999$ & .65 & $.31-1.33$ \\
\hline$\$ 20,000-34,999$ & .95 & $.40-2.25$ \\
\hline$\$ 35,000-69,999$ & 1.05 & $.56-1.98$ \\
\hline$\$ 70,000+$ & Ref & - \\
\hline \multicolumn{3}{|l|}{ Region } \\
\hline Northeast & .98 & $.51-1.87$ \\
\hline Midwest & 1.01 & $.59-1.72$ \\
\hline South & 2.18 & $1.18-4.00$ \\
\hline West & Ref & - \\
\hline \multicolumn{3}{|l|}{ Education } \\
\hline Less than high school & 1.28 & $.67-2.44$ \\
\hline High school & .90 & $.50-1.61$ \\
\hline More than high school & Ref & - \\
\hline \multicolumn{3}{|l|}{ Marital status } \\
\hline Married & .61 & $.38-.96$ \\
\hline Separated/widowed/divorced & .85 & $.47-1.57$ \\
\hline Never married & Ref & - \\
\hline \multicolumn{3}{|l|}{ Race } \\
\hline White & 1.47 & $.75-2.88$ \\
\hline Non-White & Ref & - \\
\hline \multicolumn{3}{|c|}{ DSM-IV drug use disorder preceded inhalant use } \\
\hline Yes & 2.03 & $.93-4.42$ \\
\hline No & Ref & - \\
\hline \multicolumn{3}{|c|}{ DSM-IV alcohol use disorder preceded inhalant use } \\
\hline Yes & 11.92 & $5.46-26.00$ \\
\hline No & Ref & - \\
\hline \multicolumn{3}{|c|}{ DSM-IV antisocial personality disorder or conduct disorder } \\
\hline Yes & 1.31 & $.77-2.23$ \\
\hline No & Ref & - \\
\hline \multicolumn{3}{|c|}{ DSM-IV mood and/or anxiety disorder preceded onset of inhalant use } \\
\hline Yes & 7.67 & $3.11-18.86$ \\
\hline No & Ref & - \\
\hline Age of inhalant onset, mean (S.D.) & .78 & $.73-.83$ \\
\hline \multicolumn{3}{|l|}{ Family history of behavior problems } \\
\hline Yes & .96 & $.55-1.70$ \\
\hline No & Ref & - \\
\hline \multicolumn{3}{|l|}{ Family history of SUD } \\
\hline Yes & 1.08 & $.68-1.72$ \\
\hline No & Ref & - \\
\hline
\end{tabular}

Note: Ref $=$ reference group. Values in bold are statistically significant, based on a $95 \%$ confidence interval that does not include the value 1.00 .

\subsection{Factors associated with transitions to an Inhalant Use Disorder}

Table 3 presents hazard ratios (HR) derived from a Cox regression analysis. Being married was associated with a significantly lower risk of transition to an $\mathrm{I}-\mathrm{SUD}(\mathrm{HR}=.61,95 \% \mathrm{CI}=.38-.96)$. Living in the South was also associated with twice the likelihood of transitioning compared with inhalant users living in the West $(\mathrm{HR}=2.18,95 \% \mathrm{CI}=1.18-4.00)$. Conduct disorder and/or antisocial personality disorder and family history of behavior problems were statistically significant in the unadjusted survival estimates, but were no longer significant after controlling for other factors. Having an earlier age at onset of inhalant use was associated with a significant increase in the risk of developing an I-SUD ( $\mathrm{HR}=.78,95 \%$ $\mathrm{CI}=.73-.83$ ). Comorbid DSM-IV mood/anxiety and alcohol use dis- 
(a) Median age of inhalant onset

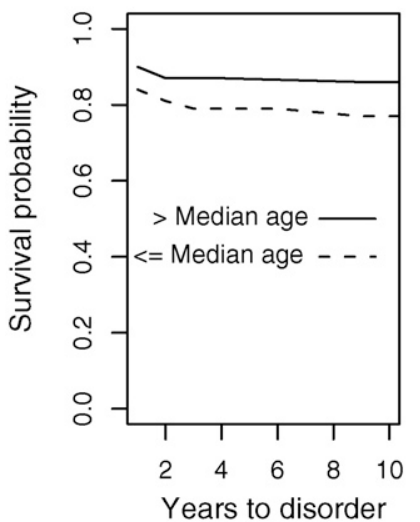

(d) DUD preceded onset of inhalant use

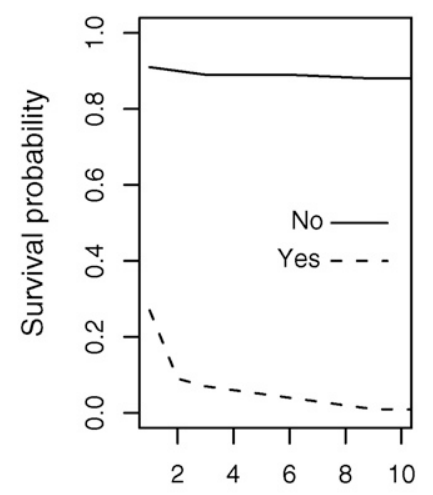

Years to disorder (b) History of ASPD or conduct disorder

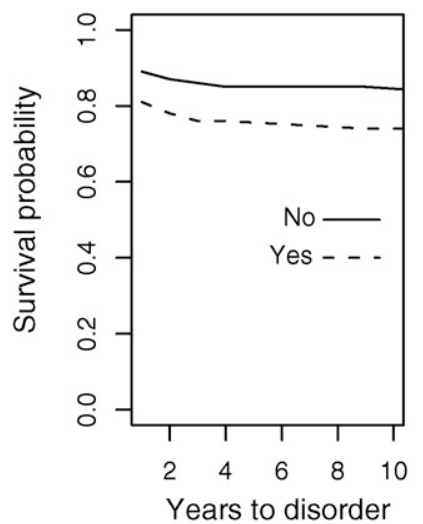

(e) Mood or anxiety disorder preceded inhalant onset

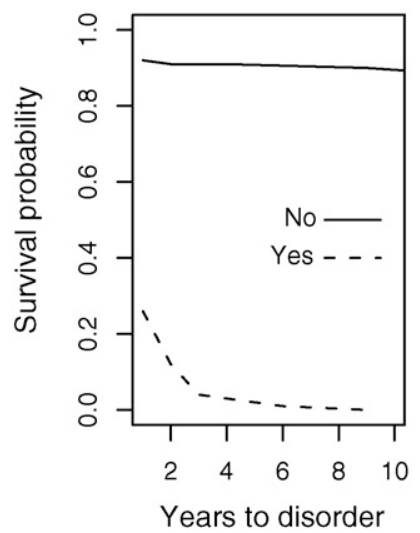

(c) AUD preceded onset of inhalant use

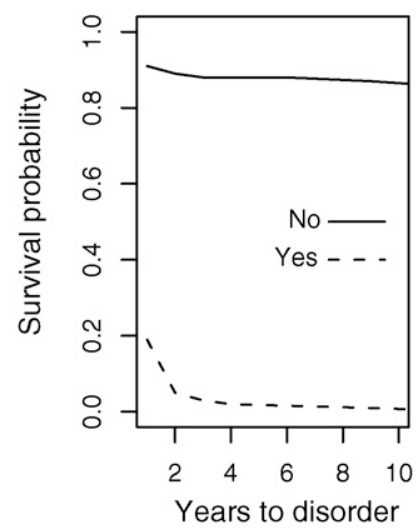

\section{(f) Family history of behavior problems}

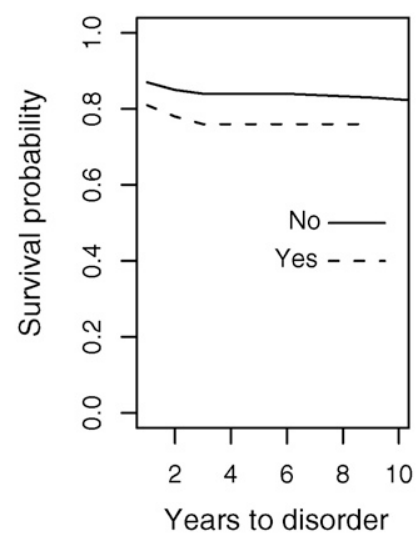

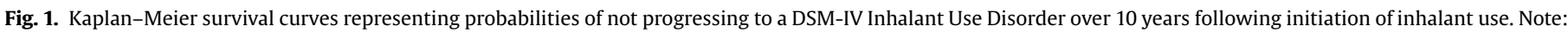

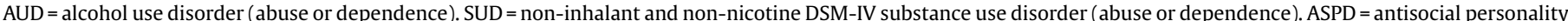

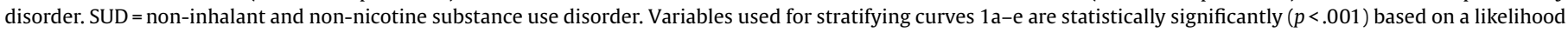
ratio test.

orders preceding onset of inhalant use were significant risk factors for I-SUDs. Specifically, inhalant users who had developed a mood or anxiety disorder prior to initiating inhalant use were at 7.67 times the risk of transitioning to a I-SUD compared with inhalant users free of comorbid anxiety and/or mood disorders, and inhalant users with an established alcohol use disorder prior to onset of inhalant use were at nearly eight times the risk ( $\mathrm{HR}=7.67,95 \%$ $\mathrm{CI}=3.11-18.86)$.

\section{Discussion}

\subsection{Prevalence, timing, and predictors of I-SUDs}

4.1.1. Abuse liability of inhalants. I-SUDs were common among lifetime inhalant users; nearly one in five such users developed an I-SUD. Inhalant users who developed I-SUDs typically evidenced a rapidly progressive and clinically significant pattern of inhalant use, such that they met DSM-IV inhalant abuse criteria within 12 months of initiating inhalant use. Inhalant abuse is defined by the presence of one or more of the following signs: a pattern of recurrent inhalant use in situations in which it is physically hazardous, recurrent inhalant-related legal problems, continued inhalant use despite having persistent or recurrent social or interpersonal problems caused or exacerbated by the effects of inhalants, and recurrent inhalant use resulting in a failure to fulfill major role obligations at work, home, or school (American Psychiatric Association, 2000). Study findings with regard to the abuse liability of inhalants accord reasonably well with the results of Ridenour et al. (2007), who reported that $27.9 \%$ of 162 community-based inhalant users met inhalant abuse criteria, and with Howard and Perron's (2008) observation that 22.2\% of 279 delinquent inhalant users met criteria for inhalant abuse. However, Ridenour et al. (2007) and Howard and Perron (2008) reported substantially higher rates of inhalant dependence among lifetime inhalant users than were observed in the present study, a difference potentially attributable to sociodemographic and clinically relevant variations in the composition of the samples studied and to the diverse assessment and diagnostic methods employed. Anthony et al. (1994) noted that only 3.7\% of lifetime inhalant users participating in the National Comorbidity Survey (NCS) met criteria for inhalant dependence, but did not report prevalence figures for inhalant abuse. It is, therefore, unknown to what extent NCS and NESARC findings for prevalence of inhalant abuse among lifetime inhalant users converge, although risk for inhalant dependence was low in both national surveys. Additional research is needed to establish the abuse liability of inhalants in different respondent populations and for different clinical outcomes (e.g., abuse vs. dependence). 
In the current study, the abuse liability of inhalants was lower in comparison to other drugs. For example, a posterori analyses of NESARC data show that the overall rates of lifetime disorders (i.e., abuse or dependence) for lifetime opioid, cannabis, and cocaine users were $30 \%, 41 \%$, and $46 \%$, respectively. It is important to note that the overall abuse liability of inhalants remains unclear, given the measurement limitations of NESARC. Specifically, hundreds of household products could be used to get high, but inhalant use was measured with a single omniibus question. Thus, the abuse liability for many specific inhalants could not be computed and compared. Future research on inhalant use would benefit from detailed examinations of the types, amounts, and modes of use.

4.1.2. Timing of transitions from inhalant use to I-SUDs. As noted above, most transitions to I-SUDs occurred in the year following onset of inhalant use and, given the comparatively early average age at onset of inhalant use, generally occurred among older adolescents and young adults. Together with other studies documenting early onset of inhalant use (Bennett et al., 2000; Prinz and Kerns, 2003; Storr et al., 2005), results of the current investigation suggest that inhalant prevention and treatment interventions will need to target youth early in life, particularly those who have recently initiated inhalant use and who otherwise present a high-risk profile for eventual progression to I-SUDs.

The average age of onset of inhalant use in this study was 17.5, significantly older than the mean ages of onset (i.e., 14-15) reported in other clinical, criminological, and general population samples of youth (e.g., Johnston et al., 2008; McGarvey et al., 1999; Siqueira and Crandall, 2006). The median age of inhalant use onset in this study was 16.2 , suggesting that the age of inhalant onset distribution was positively skewed and that a relatively small percentage of reports of inhalant use onset later in life could have significantly influenced the estimated overall mean age of inhalant use onset. Johnson and Schultz (2006) noted that retrospective reports of onset in surveys are subject to forward telescoping, a tendency on the part of respondents to report the occurrence of onset closer to the time of interviewing than is accurate. Thus, it is possible that a forward telescoping bias on the part of inhalant users who were older, may have contributed to the right skewing of the age of onset distribution and to the finding, for this sample, of a comparatively older age of onset than is typically reported.

4.1.3. Predictors of inhalant use to I-SUD transitions. Established mood, anxiety, and substance use disorders, many of them earlyonset in nature, were potent predictors of inhalant users' transitions to I-SUDs, a novel finding that extends results of recent reports (Howard et al., 2008a,b,c; Wu and Howard, 2007; Wu et al., 2008) identifying high rates of substance use and psychiatric disorders among lifetime inhalant users. Study findings are compatible with self-medication theories of inhalant use and with "third factor" accounts identifying social and biological precursors to inhalant use and other drug use and psychiatric disorders.

\subsection{Study limitations}

The findings of this study should be considered in context of its limitations. The target population for the survey was adult, noninstitutionalized, U.S. civilians; thus, military personnel, persons younger than 18 , and residents of jails, prisons, mental health institutions, and persons living on the streets with no permanent address were not included in the survey. Findings were based on participants' self-reports and consequently subject to typical limitations of self-report data, including respondents' unreliable retrospective recall, failure to report socially stigmatized behaviors such as drug use (i.e., social desirability bias), and decreasing abil- ity to access information needed to accurately answer questions over time (i.e., transience). Retrospective reports of inhalant use onset and onset of I-SUDs by persons of widely differing ages may have influenced estimation of the interval between these events in ways that are difficult to assess. It is also conceivable that use of a single ombinus inhalant assessment question may have underestimated the actual level of inhalant use in a given population (e.g., Howard et al., 2008a,b,c), but there is no evidence that this assessment approach (which is the current standard) leads to bias in the ascertainment of inhalant-using respondents. NESARC is a cross-sectional survey requiring respondents to report on the nature and timing of various events and experiences in their lives at one assessment point; thus, any reported associations must await longitudinal investigation before any causal assertions can be confidently assumed. For each of the statistically significant clinical variables, confidence intervals were wide, suggesting some unreliability in the estimates. However, effect sizes for key variables at their lower bounds, especially substance use and psychiatric disorders that preceded inhalant use, were large.

\subsection{Implications and future research}

As noted above, study findings suggest that I-SUDs develop relatively early in life and in a narrowly circumscribed period following initiation of inhalant use. Future research should examine additional features of the natural history of inhalant use including factors related to the onset of use, number and duration of I-SUD episodes over the life course, remission from I-SUDs, and eventual cessation of inhalant use and resolution of I-SUDs. The role of genetic, temperamental, psychosocial, economic, and geographic factors in inhalant use onset, escalation, maintenance, and cessation should be evaluated in carefully controlled longitudinal studies with large samples and growth curve and other relevant analytic methods. Ideally, it would be useful to assess the natural history and consequences of inhalant use for individual inhalant products of abuse, such as gasoline, given that the pharmacological properties, modes of use, consequences, and other properties of specific inhalant agents may vary significantly. Few prevention and treatment approaches targeted to adolescent inhalant users and youth at risk for initiating inhalant use have been developed or evaluated. Funding these efforts should be a priority of the National Institute on Drug Abuse and other national federal bodies, given the widespread and potentially deleterious consequences of inhalant use.

This study is the first (of which we are aware) to examine the timing and predictors of transitions from inhalant use to Inhalant Use Disorders using a survival analytic approach and a large sample of inhalant users derived from a nationally representative survey. Although longitudinal, prospective research is needed to clarify the role that substance use and psychiatric disorders play in the escalation of inhalant use following experimental use, our findings indicate that youth who initiate inhalant use early in life and who suffer from preexisting anxious-depressive disorders are at significantly elevated risk for transitions from inhalant use to abuse within the year they initiate inhalant use.

Cultural factors have received insufficient attention vis-à-vis inhalant use and could not be examined in this study due to availability of data. Prior research has found that greater westernization among Zimbabwean youth (Eide and Acuda, 1997), and greater acculturation among Hispanic youth in the U.S. (Ramirez et al., 2004), predicted inhalant use, although it is unclear why these factors were associated with increased inhalant use. Qualitative research, particularly ethnographic methods, can be useful for expanding the knowledge base on the natural history of inhalant use, abuse, and dependence, while offering a greater understanding 
to the role of cultural factors. Qualitative methods are also critical of generating new hypotheses to inform the construction of hypotheses that can be tested with survey methods. Further research is needed to better understand how individuals are introduced to inhalants and their reasons for use. For example, Perron et al.(2008) identified three distinct subgroups of adolescent users based on their reasons for use. These groups exhibited significant differences on a variety of clinical measures, including anxiety, problems associated with using substances, global symptom severity, and number of different types of inhalants used. This suggests that factors motivating individuals to use inhalants are likely a key factor to consider in the future. Qualitative methods, combined with long-term prospective studies of the natural history of inhalants are needed to develop culturally responsive prevention and treatment interventions related to inhalant use.

\section{Role of funding source}

NESARC was funded by the National Institute on Alcohol Abuse and Alcoholism with additional support provided by the National Institute on Drug Abuse. Data analysis and writing of this article was supported by grants DA021405 (Natural History, Comorbid Mental Disorders, and Consequences of Inhalant Abuse, M.O. Howard, PI), and DA15929 (Neuropsychiatric Impairment in Adolescent Inhalant Abusers, M.O. Howard, PI) from the National Institute on Drug Abuse, and by an institutional grant from the Curtis Center of the University of Michigan. Neither the National Institute on Drug Abuse nor the Curtis Center had a role in the design or conduct of the study; collection, management, analysis, and interpretation of the data; or preparation, review, or approval of the manuscript.

\section{Contributors}

All authors participated in the conceptualization of the study. The first and third authors conducted statistical analyses, and all authors participated in the manuscript preparation.

\section{Conflict of interest}

None of the authors has a financial interest or relationship with an individual or organizational entity that constitutes a conflict of interest with regard to the subject matter of this manuscript.

\section{Acknowledgement}

The authors would also like to thank Alexander Schwank for his assistance with preparing the manuscript.

\section{References}

Alper, A.T., Hasdemir, H., Nurkalem, Z., Guyler, O., Guvenc, T.S., Erdinler, I., Cakmak, N., Dksik, A., Gurkan, K., 2008. Glue (toluene) abuse: increased QT dispersion and relation with unexplained syncope. Inhal. Toxicol. 20, 37-41.

American Psychiatric Association, 2000. Diagnostic and Statistical Manual of Mental Disorder, 4th edition. American Psychiatric Association Press, Washington, DC

Anthony, J.C., Warner, L.A., Kessler, R.C., 1994. Comparative epidemiology of dependence on tobacco, alcohol, controlled substances, and inhalants: basic findings from the National Comorbidity Survey. Exp. Clin. Psychopharmacol. 3, 244-268.

Balster, R.L., 1997. Inhalant abuse: a forgotten drug abuse problem. In: College on Problems of Drug Dependence Presidential Address. Conference Proceedings, NIDA Research Monograph, vol. 174, pp. 3-8.

Bennett, M.E., Walter, S.T., Miller, J.H., Woodall, W.G., 2000. Relationship of early inhalant use to substance use in college students. J. Subst. Abuse 12, 227240.

Compton, W.M., Conway, K.P., Stinson, F.S., Colliver, J.D., Grant, B.F., 2005. Prevalence, correlates, and comorbidity of DSM-IV antisocial personality syndromes and alcohol and specific drug use disorders in the United States: results from the National Epidemiologic Survey on Alcohol and Related Conditions. J. Clin. Psychiatry 66, 677-685.
Compton, W.M., Cottler, L.B., Dinwiddie, S.H., Spitznagel, E.L., Mager, D.E., Asmus, G., 1994. Inhalant use: characteristics and predictors. Am. J. Addict. 3, 263272

Crocetti, M., 2008. Inhalants. Pediatr. Rev. 29, 33-34.

D'Abbs, P., MacLean, S., 2008. Volatile substance misuse: a review ofinterventions. Monograph Series No. 65, National Drug Strategy. Australian Government, Department of Health and Aging, ISBN: 1741865336.

Dinwiddie, S.H., 1998. Psychological and psychiatric consequences of inhalants. In: Tarter, R., et al. (Eds.), Handbook of Substance Abuse: Neurobehavioral Pharmacology. Plenum Press, New York.

Dinwiddie, S.H., 1994. Abuse of inhalants: a review. Addiction 89, 925-939.

Eide, A.H., Acuda, S.W., 1997. Cultural orientation and use of cannabis among secondary school children in Zimbabwe. Soc. Sci. Med. 45, 1241-1249.

Finch, C.K., Lobo, B.L., 2005. Acute inhalant-induced neurotoxicity with delayed recovery. Ann. Pharmacother. 39, 169-172.

Freedenthal, S., Vaughn, M.G., Jenson, J.M., Howard, M.O., 2007. Inhalant use and suicidality among incarcerated youth. Drug Alcohol Depend. 90, 129-133.

Gautschi, O.P., Cadosch, D., Zellweger, R., 2007. Postural tremor induced by paint sniffing. Neurol. India 55, 393-395.

Grant, B.F., Dawson, D.A., Stinson, F.S., Chou, P.S., Kay, W., Pickering, R., 2003. The Alcohol Use Disorder and Associated Disabilities Interview Schedule-IV (AUDADIS-IV): reliability of alcohol consumption, tobacco use, family history of depression and psychiatric diagnostic modules in a general population sample. Drug Alcohol Depend. 71, 7-16.

Grant, B.F., Harford, T., Dawson, D.A., Chou, P.S., Pickering, R.P., 1995. The Alcohol Use Disorder and Associated Disabilities Interview schedule (AUDADIS): reliability of alcohol and drug modules in a general population sample. Drug Alcohol Depend. 39, 37-44.

Howard, M.O., Balster, R.L., Cottler, L.B., Wu, L.T., Vaughn, M.G., 2008a. Inhalant use among incarcerated adolescents in the United States: prevalence, characteristics, and correlates of use. Drug Alcohol Depend. 93, 197209 .

Howard, M.O., Perron, B.E., 2008. DSM-IV inhalant use disorders among delinquent youth in the United States. Manuscript under review and available from lead author.

Howard, M.O., Perron, B.E., Sacco, P., Ilgen, M., 2008b. Suicide ideation and attempts among inhalant users: results from a national survey. Manuscript under review and available from lead author.

Howard, M.O., Perron, B.E., Vaughn, M.G., Bender, K., Garland, E., 2008c. Inhalant use, inhalant use disorders and antisocial behavior. Manuscript under review and available from lead author.

Johnson, E.O., Schultz, L., 2006. Forward telescoping bias in reported age of onset: an example from cigarette smoking. Int. J. Methods Psychiatry Res. 14, 119-121.

Johnston, L.D., O’Malley, P.M., Bachman, J.G., Schulenberg, J.E., 2008. Monitoring The Future National Results On Adolescent Drug Use: Overview Of Key Findings, 2007. National Institute on Drug Abuse, Bethesda, MD (NIH Publication No. 086418).

Lubman, D.I., Yucel, M., Lawrence, A.J., 2008. Inhalant abuse among adolescents: neurobiological considerations. Br. J. Pharmacol. 154, 316-326.

MacLean, S., 2005. 'It might be a scummy-arsed drug but it's a sick buzz': chroming and pleasure. Contemp. Drug Probl. 32 (2), 295-318.

MacLean, S., 2007. Global selves: marginalised young people and aesthetic reflexivity in inhalant drug use. J. Youth Stud. 10 (4), 399-418.

McGarvey, E.L., Clavet, G.J., Mason, W., Waite, D., 1999. Adolescent inhalant use: environments of use. Am. J. Drug Alcohol Abuse 25, 731-741.

Medina-Mora, M.E., Real, T., 2008. Epidemiology of inhalant use. Curr. Opin. Psychiat. 21, 247-251.

Oetting, E.R., Edwards, R.W., Beauvais, F., 1988. Social and psychological factors underlying inhalant abuse. In: NIDA Research Monograph, vol. 85, pp. 172-203.

Perron, B.E., Vaughn, M.G., Howard, M.O., 2008. Reasons for using inhalants: evidence for discrete classes in a sample of incarcerated adolescents. 34, 450-455

Pfeiffer, H., Khaddam, A., Brinkmann, B., Kohler, H., Beike, J., 2006. Sudden death after isobutane sniffing: a report of two forensic cases. Int. J. Legal Med. 120, $168-173$.

Prinz, R.J., Kerns, S.E., 2003. Early substance use by juvenile offenders. Child Psychiatry Hum. Dev. 33, 263-277.

Ramirez, J.R., Crano, W.D., Quist, R., Burgoon, M., Alvaro, E.M., Grandpre, J., 2004. Acculturation, familism, parental monitoring, and knowledge as predictors of marijuana and inhalant use in adolescents. Psychol. Addict. Behav. 18, 3-11.

Research Triangle Institute, 2004. SUDAAN Language Manual, Release 9. 0. Research Triangle Institute, Research Triangle Park, NC.

Ridenour, T.A., 2005. Inhalants: not to be taken lightly any more. Curr. Opin. Psychiatry $18,243-247$.

Ridenour, T.A., Bray, B.C., Cottler, L.B., 2007. Reliability of use, abuse, and dependence of four types of inhalants in adolescents and young adults. Drug Alcohol Depend. $91,40-49$.

Sakai, J.T., Hall, S.K., Mikulich-Gilbertson, S.K., Crowley, T.J., 2004. Inhalant use, abuse, and dependence among adolescent patients: commonly comorbid problems. J. Am. Acad. Child Adolesc. Psychiatry 43, 1080-1088.

Senior, K., Chenhall, R., Daniels, D., 2006. "Stuck nose”: experiences and understanding of petrol sniffing in a remote Aboriginal community. Control Drug Probl. 33, 451-472.

Seth, R., Kotwal, A., Ganguly, K., 2005. Street and working children of Delhi, India, misusing toluene: an ethnographic exploration. Subst. Use Misuse 40, 1659-1679. 
Siqueira, L.M., Crandall, L.A., 2006. Inhalant use in Florida youth. Subst. Abuse 27, 27-35.

Storr, C.L., Westergaard, R., Anthony, J.C., 2005. Early onset inhalant use and risk for opiate initiation by young adulthood. Addict. Behav. 32, 248-264.

Weintraub, E., Gandhi, D., Robinson, C., 2000. Medical complications due to mothball abuse. South Med. J. 93, 427-429.

Williams, J.F., Storck, M., and the Committee on Substance Abuse and Committee on Native American Child Youth, 2007. Pediatrics. 119, 1009-1017.
Wu, L.T., Howard, M.O., 2007. Psychiatric disorders in inhalant users: results from the National Epidemiologic Survey on Alcohol and Related Conditions. Drug Alcoho Depend. 88, 146-155.

Wu, L.T., Howard, M.O., Pilowsky, D.J., 2008. Substance use disorders among inhalan users: results from the National Epidemiologic Survey on Alcohol and Related Conditions. Addict. Behav. 33, 968-973.

Wu, L.T., Ringwalt, C.L., 2006. Inhalant use and disorders among adults in the United States. Drug Alcohol Depend. 85, 1-11. 